\title{
The effect of endotoxin adsorber hemoperfusion on microcirculation in patients with severe sepsis and septic shock
}

\author{
Y-C Yeh ${ }^{1 *}$, Y-C Hsu ${ }^{1}$, A Chao ${ }^{1}$, V-C Wu${ }^{2}$, W-H Sheng ${ }^{2}$, C-C Kao ${ }^{3}$, Y-J Cheng ${ }^{1}$, \\ NTUH Center of Microcirculation Medical Research (NCMMR)
}

From ESICM LIVES 2015

Berlin, Germany. 3-7 October 2015

\section{Introduction}

Microcirculatory dysfunction may result in multiple organ dysfunction during severe sepsis and septic shock.

(1) A meta-analysis of randomized trials showed that polymyxin B hemoperfusion (PMX-HP), plasma exchange, and hemofiltration were associated with lower mortality.

(2) Mesenteric microcirculation was better maintained with polymyxin B hemoperfusion in one rat sepsis study.

(3) However, the effects of polymyxin B hemoperfusion on the microcirculation in patients with severe sepsis and septic shock was unknown.

\section{Objectives}

The aim of this clinical study is to investigate the effect of polymyxin $\mathrm{B}$ perfusion on the microcirculation.

\section{Methods}

This multi-center, randomized, controlled study was approved by the National Taiwan University Hospital Research Ethics Committee, which is registered on the ClinicalTrials.gov Protocol registration system (ID: NCT01756755). Forty patients with definitive treatment of severe sepsis and septic shock, which was caused by intra-abdominal infection or proven gram-negative infection, or presence with an Endotoxin Activity Assay (EAA) > 0.6 EAA units, will be randomly assigned to two groups: the Control group and the PMX-HP group. In the Control group, the patients were treated according to the Surviving Sepsis Campaign guidelines. In the PMXHP group, the patients were treated with an additional

${ }^{1}$ National Taiwan University Hospital, Department of Anesthesiology, Taipei, Taiwan, Province of China

Full list of author information is available at the end of the article treatment with 1 to 2 sessions of polymyxin B hemoperfusion. A sidestream dark-field video microscope was used to record the images of sublingual microcirculation at enrollment $(0 \mathrm{~h}), 24 \mathrm{~h}$ and $48 \mathrm{~h}$. The images was analyzed by an investigator blinded to the clinical data and grouping using an automated analysis software (AVA 3.0; Academic Medical Centre, The Netherlands).

\section{Results}

13 patients completed the study. The mean of APCHE II score at enrollment was 18.7 (5.9). 12 patients survived more than 28 days, and 1 patient died in the PMX-HP group. The total small vessel density and perfused small vessel density at $24 \mathrm{~h}$ and $48 \mathrm{~h}$ were higher in the PMX-HP group than in the Control group (Table 1).

The differences of microvascular flow index and heterogeneity between the two groups were not significant (Table 2).

The images of sublingual microcirculation at $24 \mathrm{~h}$ and $48 \mathrm{~h}$ were shown in the Figure 1.

\section{Table 1}

\begin{tabular}{lllll}
\hline & & Control & PMX-HP & P value \\
\hline $\mathbf{n}$ & & $\mathbf{6}$ & $\mathbf{7}$ & \\
\hline Total SVD $(\mathrm{mm} / \mathrm{mm} 2)$ & $0 \mathrm{~h}$ & $21.7(2.2)$ & $23.2(2.4)$ & 0.286 \\
\hline & $24 \mathrm{~h}$ & $19.3(2.2)$ & $21.8(0.9)$ & 0.190 \\
\hline & $48 \mathrm{~h}$ & $19.4(1.5)$ & $22.8(0.7)$ & 0.001 \\
\hline Perfused SVD $(\mathrm{mm} / \mathrm{mm} 2)$ & $0 \mathrm{~h}$ & $18.6(4.5)$ & $20.5(5.5)$ & 0.523 \\
\hline & $24 \mathrm{~h}$ & $18.0(2.2)$ & $21.2(1.3)$ & 0.007 \\
\hline & $48 \mathrm{~h}$ & $18.2(1.6)$ & $22.2(0.6)$ & $<0.001$ \\
\hline
\end{tabular}

[Small vessel density (SVD)] 
Table 2

\begin{tabular}{llll}
\hline & & Control & PMX-HP \\
\hline Microcvascular flow index & $0 \mathrm{~h}$ & $2.6(0.5)$ & $2.7(0.4)$ \\
\hline & $24 \mathrm{~h}$ & $2.9(0.2)$ & $3.0(0.0)$ \\
\hline Heterogeneity index & $48 \mathrm{~h}$ & $2.9(0.2)$ & $3.0(0.0)$ \\
\hline & $0 \mathrm{~h}$ & $0.21(0.21)$ & $0.21(0.29)$ \\
\hline & $24 \mathrm{~h}$ & $0.17(0.23)$ & $0.03(0.08)$ \\
\hline
\end{tabular}

[Microvascular flow and heterogeneity]
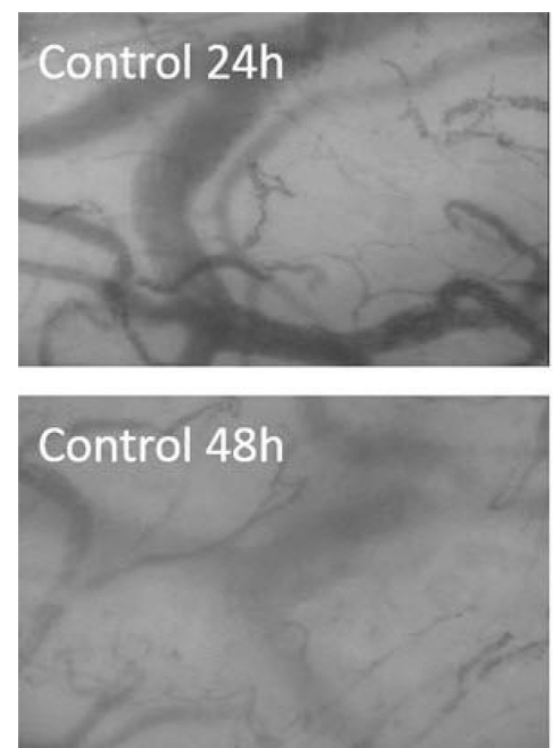

Figure 1 Sublingual microcirculation

There were no significant difference of mean arterial pressure, dose of vasopressor, serum level of lactate, creatinine, amount of fluid resuscitation, stay in the intensive care unit, and stay in hospital between the two groups.

\section{Conclusions}

In summary, we found that sublingual microcirculation was better maintained with polymyxin B hemoperfusion than conventional treatment in patients with severe sepsis and septic shock.

\section{Authors' details}

${ }^{1}$ National Taiwan University Hospital, Department of Anesthesiology, Taipei,

Taiwan, Province of China. ${ }^{2}$ National Taiwan University Hospital, Department of Internal Medicine, Taipei, Taiwan, Province of China. ${ }^{3}$ Taipei Medical

University Hospital, Department of Internal Medicine, Taipie, Taiwan, Province of China.

Published: 1 October 2015

\section{References}

1. Ince C: Critical care 2005, 9(Suppl 4):S13-9.
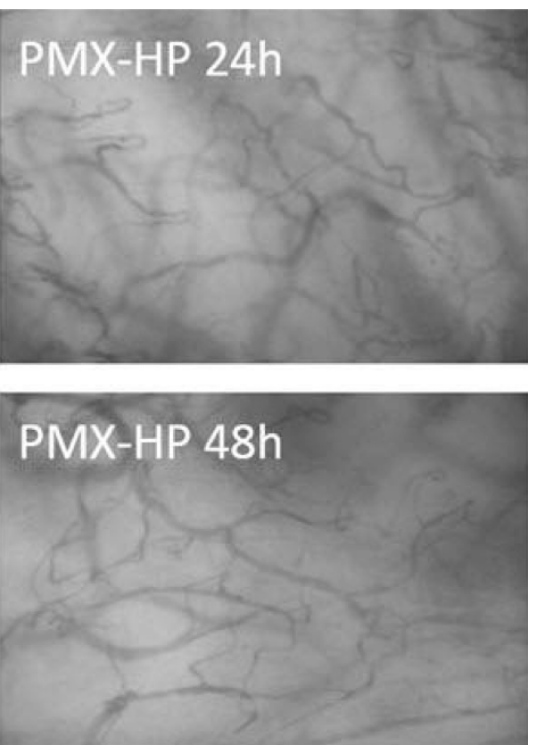

2. Zhou, et al: Crit Care Med 2013, 41:2209-20.

3. Iba, et al: J Surg Res 2011, 171:755-61.

doi:10.1186/2197-425X-3-S1-A810

Cite this article as: Yeh et al:: The effect of endotoxin adsorber

hemoperfusion on microcirculation in patients with severe sepsis and septic shock. Intensive Care Medicine Experimental 2015 3(Suppl 1):A810.

\section{Submit your manuscript to a SpringerOpen ${ }^{\mathcal{O}}$ journal and benefit from:}

- Convenient online submission

- Rigorous peer review

- Immediate publication on acceptance

- Open access: articles freely available online

- High visibility within the field

- Retaining the copyright to your article

Submit your next manuscript at $>$ springeropen.com 